\title{
The population biology and evolutionary significance of Ty elements in Saccharomyces cerevisiae
}

\author{
C. M. Wilke, E. Maimer \& J. Adams* \\ Department of Biology, University of Michigan, Ann Arbor, MI 48109, USA \\ * author for correspondence
}

Received 13 March 1992 Accepted 13 March 1992

\begin{abstract}
The basic structure and properties of Ty elements are considered with special reference to their role as agents of evolutionary change. Ty elements may generate genetic variation for fitness by their action as mutagens, as well as by providing regions of portable homology for recombination. The mutational spectra generated by Tyl transposition events may, due to their target specificity and gene regulatory capabilities, possess a higher frequency of adaptively favorable mutations than spectra resulting from other types of mutational processes. Laboratory strains contain between 25-35 elements, and in both these and industrial strains the insertions appear quite stable. In contrast, a wide variation in Ty number is seen in wild isolates, with a lower average number/genome. Factors which may determine Ty copy number in populations include transposition rates (dependent on Ty copy number and mating type), and stabilization of Ty elements in the genome as well as selection for and against Ty insertions in the genome. Although the average effect of Ty transpositions are deleterious, populations initiated with a single clone containing a single Ty element steadily accumulated Ty elements over 1,000 generations. Direct evidence that Ty transposition events can be selectively favored is provided by experiments in which populations containing large amounts of variability for Ty 1 copy number were maintained for $\sim 100$ generations in a homogeneous environment. At their termination, the frequency of clones containing 0 Ty elements had decreased to $\sim 0.0$, and the populations had became dominated by a small number of clones containing $>0$ Ty elements. No such reduction in variability was observed in populations maintained in a structured environment, though changes in Ty number were observed. The implications of genetic (mating type and ploidy) changes and environmental fluctuations for the long-term persistence of Ty elements within the $S$. cerevisiae species group are discussed.
\end{abstract}

\section{Introduction}

Transposable elements are found throughout the five biological kingdoms. Although they have attracted a great deal of attention from molecular and population biologists alike, their importance and role in evolutionary change remain controversial (Syvanen, 1984; Finnegan, 1989). Two alternative hypotheses have been advanced to explain the ubiquity of transposable elements in nature. The first postulates that they are primarily parasites which have evolved extraordinarily successful mechanisms for their self-maintenance, while the second postulates that they play a positive role in creating genetic adaptive genetic variation.
The assertion that the primary evolutionary role of transposable elements is negative is an argument which really owes its allegiance to the neo-classical school of population genetics (Lewontin, 1974). The early influential paper of Doolittle and Sapienza (1980) is an eloquent statement for this viewpoint. One property of transposable elements which has been invoked in support of this hypothesis is their ability to generate mutations, many of which may be deleterious. In Drosophila, the movement of $\mathrm{P}$ elements generally decreases fitness (Fitzpatrick \& Sved, 1986; Mackay, 1986). Furthermore, the distributions of transposable elements in the genomes of Drosophila and $E$. coli provide indirect evidence for a deleterious effect increasing with 
copy number (Sawyer et al., 1987; Charlesworth \& Langley, 1989). A corollary to the argument that the evolutionary role of transposable elements is primarily negative is that systems have evolved to limit the number of elements in the genome. Evidence for copy number control exists for several transposable elements of both prokaryotes and eukaryotes (Kleckner, 1990; Laski, Rio \& Rubin, 1986; Misra \& Rio, 1990), in which the regulation of transposition has been well characterized.

The alternative hypothesis, that transposable elements have a positive evolutionary role in creating adaptive genetic variation, can be considered to belong to the balance school of population genetics (Lewontin, 1974). Direct and indirect evidence in both prokaryotes (Kurlandzka, Rosenzweig \& Adams, 1991) and eukaryotes (Finnegan, 1989; McDonald, 1990 and references therein) has pointed to regulatory mutations as the primary source of genetic variation that allows organisms to adapt to new environments. There is a growing body of evidence that transposable elements of many types target transcriptionally active areas of the genome (Sandmeyer, Hansen \& Chalker, 1990) and show preference for the $5^{\prime}$ regions of genes (Voelker et al., 1990). The activation of cryptic genes and the modification of gene regulation are frequently found to result from transposable element integration (Stavenhagen \& Robins, 1988; Lopilato \& Wright, 1990). It is therefore possible that the mutational spectra generated by transposable elements possess a higher frequency of adaptively favorable changes as compared to the mutational spectra from base substitutions (or small additions and deletions). Increases in fitness coupled with transposition have been reported in both $E$. coli (Chao et al., 1983; Chao \& McBroom, 1985; Modi et al., 1992) and Drosophila (Pasyukova et al., 1986, 1988; cf. Mackay, 1985, 1986; Shrimpton, Mackay \& Leigh Brown, 1990).

In this review, we examine the evolutionary significance and population biology of the Ty family of transposable elements in Saccharomyces cerevisiae.

\section{Basic structure and properties of transposable elements in Saccharomyces cerevisiae}

Four different families of transposable elements have been identified in $S$. cerevisiae, termed Ty 1 , Ty2, Ty3 and Ty4 (Cameron, Loh \& Davis, 1979; Clark et al., 1988; Stucka, Lochmuller \& Feldmann, 1989), and all four are structurally similar to the copia-like elements of Drosophila, as well as to the endogenous retroviruses of higher eukaryotes. The Ty1 and Ty 2 families of elements are closely related, sharing approximately $60 \%$ of their sequences. Accordingly, many studies have shown that the regulation of expression of these two elements is similar and that they share the same general target specificity. Ty 1 , Ty2, and Ty3 elements have all been shown to encode virus-like particles containing reverse transcriptase, and Ty 1 has been shown directly to transpose through an RNA intermediate (Boeke et al., 1985; Garfinkel, Boeke \& Fink, 1985; Hansen, Chalker \& Sandmeyer, 1988; Hansen \& Sandmeyer, 1990). All four Ty families share the same basic structure, consisting of two directly-oriented terminal repeats (LTRs) of 330-370 base pairs, known as delta (Ty1 or Ty2), sigma (Ty3) or tau (Ty4) elements, flanking a central coding region of 4.7-5.5 kb, known in the Tyl family as the epsilon region. In all four families, this central region contains DNA and/or amino acid sequence homologies to the gag and pol regions of retroviruses (Clare \& Farabaugh, 1985; Warmington et al., 1985; Hansen, Chalker \& Sandmeyer, 1988; Stucka, Lochmuller \& Feldmann, 1989), but differences exist in the order in which the pol-encoded functions are arranged (Mellor, Kingsman \& Kingsman, 1986; Hansen, Chalker \& Sandmeyer, 1988). The molecular biology and the mechanism of action of these elements continues to be an active area of research, and several comprehensive reviews have recently appeared on these topics (Boeke, 1989; Boeke \& Garfinkel, 1988; Liebman \& Picologlou, 1988). For the remainder of this review, we focus on the Tyl family, for which the most information is available.

\section{The Tyl family of elements}

Due to their similarity, many features of the structure and properties of the Tyl family of elements also apply to Ty 2 elements. Throughout this paper, the abbreviation Ty will refer to both families, while Tyl will denote this family specifically.

Although there is some minor variation among Ty1 elements in the genome (Boeke, 1989), a typi- 


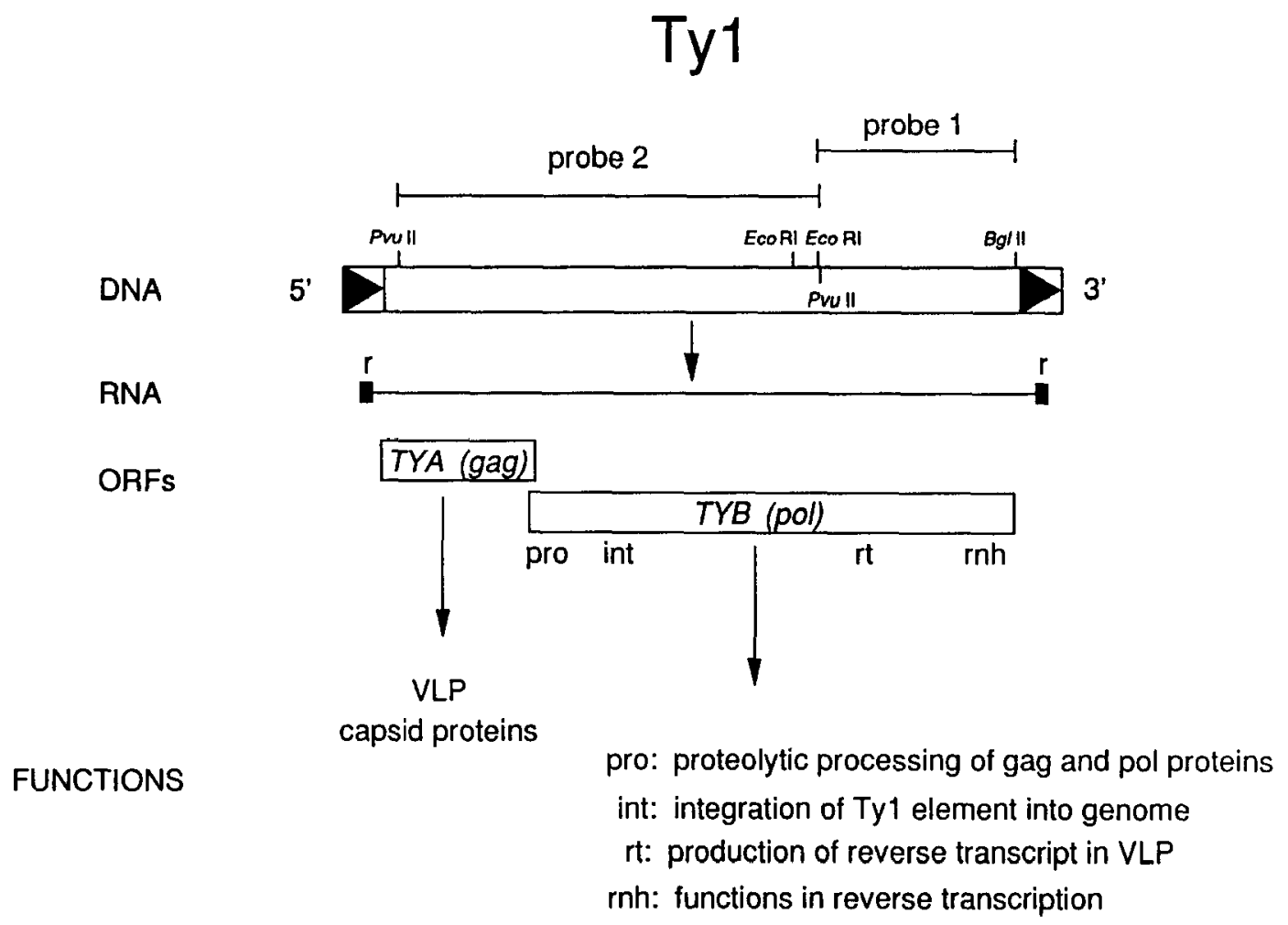

Fig. 1. Ty 1 structure, expression and functions (after figures from Boeke \& Garfinkel, 1988, and Kingsman \& Kingsman, 1988). Shown is a schematic representation of the expression sequence of Ty 1 elements from the DNA form to the protein functions. The triangles represent the $\sim 335$ bp delta elements, and the large open box is the epsilon region. The nearly full length transcript is shown as a line with small solid boxes representing the short terminal redundancy (r) at the $5^{\prime}$ and $3^{\prime}$ ends. The TYA (gag) and TYB(pol) open reading frames are depicted as open rectangles which overlap slightly. The translational frameshift resulting in the TYA-TYB fusion protein occurs about $5 \%$ of the time that the TYA ORF is translated alone (Clare, Belcourt \& Farabaugh, 1988; Wilson et al., 1986). The general positions in the TYB ORF that have homology to, and/or have been shown to encode the biochemical functions for proteins identified in retroviruses, are indicated by the lower case letters below the TYB box. VLP capsid proteins are the nucleocapsid proteins of the Ty 1 virus-like particle; pro, an acid protease involved in processing; int, integrase enzyme; rt, reverse transcriptase; mh, RNase $H$ (Boeke, 1989). Several well conserved restriction enzyme sites are shown to demarcate the ends of probes used in DNA - DNA hybridization experiments described in the text. Probe 1 was used as a $3^{\prime}$ specific probe, probe 2 as a $5^{\prime}$ specific probe.

cal element consists of two directly oriented terminal delta elements, which can vary in size from 331 to $338 \mathrm{bp}$, flanking a central epsilon region of approximately $5.2 \mathrm{~kb}$ (Fig. 1). There are $25-30 \mathrm{com}-$ plete Ty1 elements/haploid genome in laboratory strains of $S$. cerevisiae, and approximately 100 copies of the delta elements, many of which are not associated with Ty elements (Cameron, Loh \& Davis, 1979). The elements contain two open reading frames, TYA and TYB, which together originate in the $3^{\prime}$ delta and continue through most of the epsilon region. As is true for the gag and pol genes in a number of other retroelements, these two cod- ing regions overlap, with the $T Y B$ gene in a +1 reading frame relative to TYA (Clare \& Farabaugh, 1985; Mellor et al., 1985a). The TYBI-encoded functions are ultimately expressed through the proteolytic processing of a TYA-TYB fusion protein that results from a frameshift during translation (Adams et al., 1987; Müller et al., 1987; Youngren et al., 1987).

The Ty 1 transcript initiates in the $5^{\prime}$ delta and terminates in the $3^{\prime}$ delta, resulting in a nearly full length mRNA that has short terminal repeats of about 45 bp (Elder, Loh \& Davis, 1983) (Fig. 1). Translation of this message results in the formation 
of virus-like particles (VLPs) (Garfinkel, Boeke \& Fink, 1985; Mellor et al., 1985b) which are an essential intermediate in Ty 1 transposition (Youngren et al., 1987). These particles sequester Tyl RNA, reverse transcriptase, integrase and other components utilized in the transposition process. The overexpression of Ty 1 elements from heterologous promoters results in the formation of numerous VLPs, and under some conditions a greatly increased rate of transposition (Boeke et al., 1985). Upon transposition, Tyl elements cause a five bp duplication of the genomic target sequence (Farabaugh \& Fink, 1980; Gafner \& Philippsen, 1980).

Although Ty1 elements are found distributed throughout the genome, their distribution suggests that certain regions are preferred targets for transposition. When sheared DNA was fractionated on $\mathrm{Ag}^{+} / \mathrm{CsSO}_{4}$ density gradients, Ty elements were found to be preferentially associated with the $\mathrm{A} / \mathrm{T}$ density class, and under-represented in the $\mathrm{G} / \mathrm{C}$ rich class (Oyen \& Gabrielsen, 1983). The distribution of tRNA genes is also skewed toward the A/T rich fraction of the yeast genome, and indeed, Tyl elements and solo deltas are frequently found $5^{\prime}$ to tRNA genes, along with composite elements and LTRs from other Ty families (Gafner, De Robertis \& Philippsen, 1983). However, the loose consensus sequences derived from studies of the five bp duplications from many Tyl integrations indicate that base content alone is not an overriding parameter in Ty1 target site selection (Natsoulis et al., 1989, Wilke et al., 1989). It seems more likely that the preferred sites for Ty1 transposition are influenced by local chromatin structure, as is apparently the case for many retroviruses in higher eukaryotes (Sandmeyer, Hansen \& Chalker, 1990).

Since Tyl elements transpose through an RNA intermediate (Boeke et al., 1985), levels of Tyl transcription can directly influence rates of Tyl transposition. A number of genetic factors, including the mating-type locus (see below), influence the expression of Tyl elements, and several host genes have been identified as being necessary for Tyl transcription (see Boeke, 1989). The effect of many mutations in these genes is to decrease or abolish the production of normal transcripts from Tyl elements, which in turn prevents or greatly reduces Tyl transposition.

In addition, at least two genes have been isolated which act at the post-transcriptional level to modify the rate of Ty 1 transposition. The overexpression of a rare species of tRNA, involved in the reading of the codons in the Ty $1 \mathrm{mRNA}$ where the TYA and TYB genes overlap, decreases the amount of TYB encoded proteins by reducing the frequency of frameshifting during translation (Xu \& Boeke, 1990). Picologlou, Brown and Liebman (1990) showed that mutations in the $R A D 6$ gene, which encodes a ubiquitin-conjugating enzyme specific for the $\mathrm{H} 2 \mathrm{~A}$ and $\mathrm{H} 2 \mathrm{~B}$ histones, stimulates Ty 1 transposition 100 fold at $30^{\circ} \mathrm{C}$ by an uncharacterized mechanism.

Several environmental factors have been shown to influence Ty 1 transcription and transposition, including temperature, carbon-source, ultraviolet light and ionizing radiation. When $S$. cerevisiae is grown at optimum temperatures $\left(\sim 30^{\circ} \mathrm{C}\right)$, the percentage of spontaneous mutations caused by Ty transposition has been estimated to range from $2 \%$ to $6 \%$ (Eibel \& Philippsen, 1984; Paquin \& Williamson, 1986; Giroux et al., 1988). At this temperature, the transposition rate has been estimated to be $\sim 2 \times 10^{-9}$ to $2-3 \times 10^{-10}$ per cell division (Paquin \& Williamson, 1986; Boeke, Styles \& Fink, 1986). However, when yeast is grown between $15^{\circ} \mathrm{C}$ and $22^{\circ} \mathrm{C}$, Ty transposition rates are increased 20 to 100 -fold (Paquin \& Williamson, 1984; Paquin \& Williamson, 1986; Boeke, Styles \& Fink, 1986). At this low temperature, the Ty transposition rate has been estimated at $\sim 1 \times 10^{-7}$ per cell division, and has been shown to account for $90 \%$ to $100 \%$ of the mutations that alter gene regulation (Paquin \& Williamson, 1986). Under these conditions Boeke (1989) estimated that a Ty transposition event occurs in $\sim 1 \%$ of all cell divisions.

Growth on glycerol rather than glucose (Taguchi, Ciriacy \& Young, 1984) has been shown to reduce Ty transcription, whereas ultraviolet light stimulates transcription (McClanahan \& McEntee, 1984; Rolfe, Spanos \& Banks, 1986). Similarly, exposure to gamma radiation has been shown to increase the fraction of Ty mutations among induced mutations (Morawetz, 1987). Genetic and environmental factors may also interact to modulate the Ty transcription rate. Although the transposition rate is reduced in both haploid and diploid cells grown on glycerol (as compared to that for cells grown on glucose), the reduction is proportionately larger in mating competent diploids (Taguchi, Ciriacy \& Young, 1984; Paquin \& Williamson, 1986). 


\section{Ty elements as mutagens}

The significance of Ty 1 elements in evolution rests on their ability to generate mutations. Many spontaneous mutations in yeast, in both structural and regulatory regions of genes, have been attributed to Tyl transposition events (Boeke, 1989). As is the case with other mutagens, it is reasonable to assume that most of the mutations caused by Tyl elements are likely to be deleterious or neutral (cf. Goebl \& Petes, 1986). However, the mutational spectra generated by Tyl transposition events may, due to their target specificity and gene regulatory capabilities, possess a higher frequency of adaptively favorable mutations than spectra resulting from other types of mutational processes. Several workers have now shown that Tyl elements insert preferentially into the $5^{\prime}$ and regulatory regions of genes (Eibel \& Philippsen, 1984; Simchen et al., 1984; Natsoulis et al., 1989; Wilke et al., 1989). For example, Ty1 elements integrate into the $5^{\prime}$ region of the lys 2 gene approximately nine times more frequently than into the central region of the gene (Natsoulis et al., 1989). In addition, several studies have indicated that when normal laboratory strains are challenged under conditions that demand regulatory changes in the expression of specific loci, Ty transposition is frequently responsible for mediating these changes. Thus, selection for constitutive expression under repressing conditions at both the $P H O 5$ and $A D H 2$ loci resulted in mutations mediated by Ty elements (Toh-e et al., 1983; Williamson, Young \& Ciriacy, 1981). Ty element insertions have also been shown to be responsible for activation of the cryptic $A D H 4$ gene (Paquin \& Williamson, 1986) and for an increase in the expression of the normally poorly expressed $\mathrm{CYC7}$ locus (Errede et al., 1980). Furthermore, the primary mechanism whereby the promoterless his $3 \Delta 4$ allele is activated is through the transposition of Ty elements (Scherer, Mann \& Davis, 1982; Boeke et al., 1985; Boeke, Styles \& Fink, 1986). Conversely, mutations conferring resistance to stress (heat shock, UV light and ethanol) have been found to result from the integration of Ty elements into the essential adenylate cyclase gene, CYR1, in such a way as to decrease the expression of this locus three fold (Iida, 1988).

Generally, when a gene is placed under the control of a neighboring Ty element, the expression of that gene becomes regulated by the mating-type locus, as Ty transcription itself is dependent on the mating type of the cell (see below) (Errede $e t$ al., 1980). Thus, Ty elements, like other transposable elements and retroviruses (McDonald, 1989), may not only alter the level of transcription, but they may change the pattern of gene expression. Clearly, transposition events that have the potential to bring a gene under the control of different regulatory machinery of the cell have considerable evolutionary significance.

\section{Ty elements as recombinogenic agents}

In addition to transposition, numerous studies have documented that homologous recombination between dispersed Ty and delta elements can lead to a variety of chromosomal structural changes (reviewed by Liebman \& Picologlou, 1988). Therefore, Ty element transposition can disrupt the genome by both the integration of foreign sequences, and by providing portable regions of homology for subsequent rearrangement. This would suggest that an increase in Ty copy number would be deleterious independent of the effects of the individual Ty insertions, due to the increased opportunity for ectopic recombination. However, there is no evidence for an increased frequency of gross chromosomal rearrangements in strains with high copy number (Boeke, Eichinger \& Natsoulis, 1989).

\section{The natural history of Ty elements}

Stability of Ty copy number in laboratory and industrial strains

The Ty elements of laboratory strains have been found to be generally stable. The mutations they cause can be used as non-reverting markers (Rose \& Winston, 1984; Garfinkel \& Strathern, 1991), and individual elements can be mapped by conventional genetic approaches (Klein \& Petes, 1984). It has also been observed that isogenic strains separated for years in different laboratories still maintain identical or nearly identical Ty hybridization spectra (Cameron, Loh \& Davis, 1979). Similarly, bottom fermenting lager strains currently being used in breweries in America and throughout Eu- 
rope, which were disseminated from a few sources over the last 2 centuries, show closely related Ty hybridization patterns (Pedersen, 1985, 1986). Furthermore, hybridization of Tyl DNA probes to chromosomes resolved by pulse-field gel electrophoresis showed the presence of Ty elements in the same five chromosomes in all of these lager strains. It has also been observed that the Ty hybridization patterns of two different sets of Stroh's Brewery strains are nearly identical, even though the related clones have been separated by more than $\sim 7,000$ generations (Wilke, Joventino \& Adams, unpublished data). In spite of this apparent stability over long periods of time, wild isolates of $S$. cerevisiae show large differences in Ty copy number, and populations of yeast maintained in continuous culture in the laboratory do show evidence of Ty copy number changes, albeit at a low level, as discussed below.

\section{Variation in Ty copy number in wild isolates}

Given the apparent stability of Ty insertions, it is perhaps surprising that wild isolates of $S$. cerevisiae show wide variation in Ty copy number. An earlier survey (Eibel et al., 1980; Philippsen et al., 1983) for a limited number of isolates reported variation in Ty copy number among wild yeast.

Figure 2 shows the distribution of Ty element copy number in 88 wild strains identified as $S$. cerevisiae (see figure legend for details) obtained from two collections (H. Phaff; Maimer, 1990) and isolated from a variety of sources, including fruits, fruit juices, wine, beer, oriental food, cheese, bread, insects, tree exudates and infections in humans. The range of variation can also be seen in Figure 3 which shows the hybridization spectra for a subset of 15 wild isolates. No strains isolated from the wild were free of Ty elements. The distribution appears to be quite complex, with the suggestion of three modes at copy numbers of 11,19 and 28 . However, models of variation in copy number generally predict unimodal distributions (Sawyer et al., 1987), with the exact form of the distribution being dependent on the nature of the functions describing copy numbers increase (i.e., regulation or not, of copy number) and decrease (i.e. selection against copy number). Not surprisingly therefore, none of the models of Sawyer et al. (1987) gave an adequate fit to the data shown in Figure 2. It is more

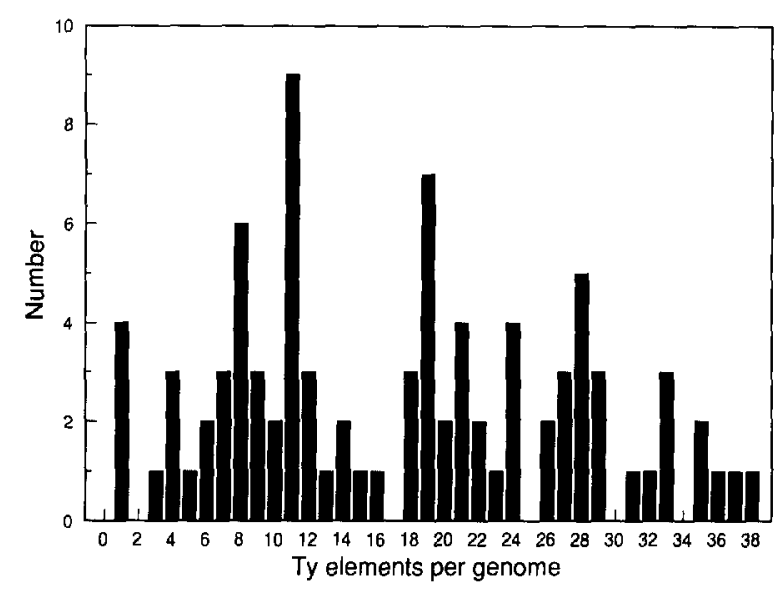

Fig. 2. The distribution of the number of Ty elements/genome for 88 wild isolates examined. The average number of Tys/ genome is 17.45 (standard deviation, 9.91). The origin of the strains is described in the text. All of the strains were reidentified as $S$. cerevisiae by using assimilation tests which included 30 carbon compounds and 7 nitrogen compounds, growth on $0.01 \%$ and $0.1 \%$ cyclohexamide, and the ability to hydrolyse urea. The results of these tests were compared to the specific characteristics table of Barnett et al. (1983).

likely that the distribution of Ty copy number reflects a heterogeneity in the sample of wild isolates. This heterogeneity cannot be explained by the source of the isolates, as the apparent trimodality is seen for strains isolated from either fruit, beer, wine or miscellaneous sources (Maimer \& Adams, unpublished). However, it is well known that wild yeast isolates can be of varying ploidy level, and there is some suggestion that the trimodal distribution of Ty copy number is at least partially due to differing ploidy levels. Ploidy level was estimated for a subset of twelve wild isolates by cell flow cytometry (Puskas-Rozsa \& Adams, unpublished), and the Ty copy number for tetraploid strains (29) was higher than that for triploid and diploid strains (21). Strains that are triploid and higher may also be expected to exhibit a larger number of bands on pulse-field gels, representing chromosomes of different sizes, and a significant $(\alpha<0.05)$ correlation exists (Maimer \& Adams, unpublished data) between the number of chromosomal bands and Ty copy number for the isolates analyzed in Figure 2. We therefore analyzed the distribution of Ty copy number among isolates with 0 to 17 Ty copies for fit to the models of Sawyer and Hartl (1986), on the assumption that this subset represented a homoge- 
neous category. The results (Table 1) indicate that 15 different models provide an adequate fit to the data, and that all of these models (see Table 1 Notes for details of these models) describe some form of copy number control.

The variation seen among wild isolates of $S$. cerevisiae when considered in the context of the apparent stability of Ty insertions, suggests that the pattern of Ty insertions revealed by hybridization spectra may allow the determination of origins of isolates and similarities between strains, much in the same way that RFLPs have been used (Pedersen, 1988). For example, Ty hybridization spectra confirmed that a yeast strain responsible for spoil- age of a production run of processed fruit and fruit yogurts originated from one company supplying kiwi fruit (Maimer \& Adams, unpublished data).

\section{Factors determining Ty copy number in popula- tions}

Ty virus-like particles have no extracellular phase and are not infective (Boeke \& Garfinkel, 1988). Therefore the wide distribution of Ty elements among isolates of the $S$. cerevisiae species group appears to be the product of an initial introduction and vertical transmission within the precursors of

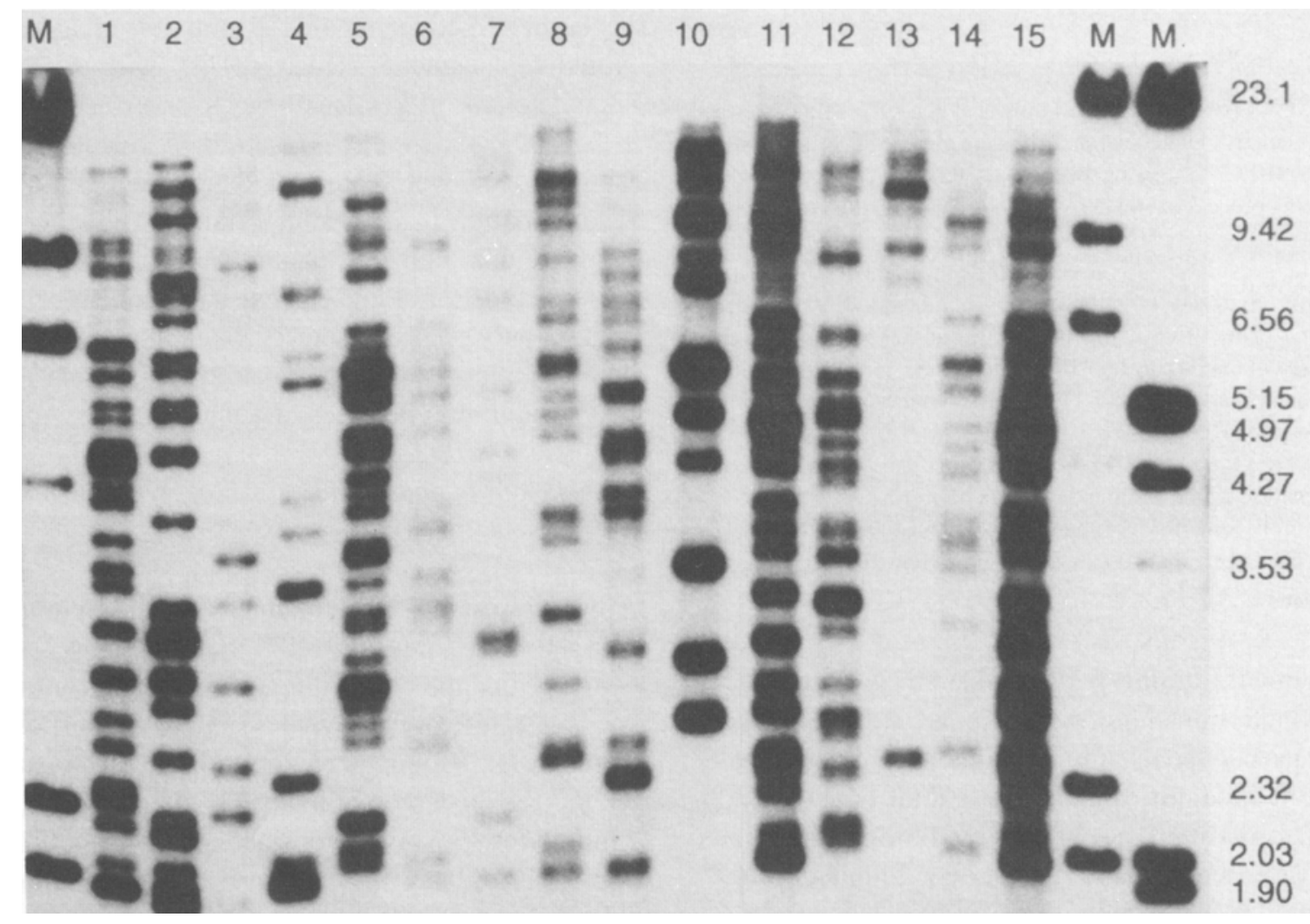

Fig. 3. Hybridization spectra for a subset of $15 / 88$ wild isolates analyzed for Ty copy number. DNA from wild strains was digested with EcoRI, and the fragments resolved by electrophoresis in a $0.7 \%$ agarose gel, transferred to a nylon membrane and hybridized with a ${ }^{32} \mathrm{P}$-labelled, 3' specific Ty 1 probe (Fig. 1, probe 1). Since the EcoRI restriction sites in Tyl elements are highly conserved, each band on the gel should represent the $3^{\prime}$ end of at least one Tyl element. Band intensity was taken into consideration in estimating the number of elements in each strain. Since probe 1 is not specific to Ty 1 elements, the closely related Ty2 elements are also seen in these spectra. Ty 2 elements lack EcoRI restriction sites, and therefore are expected to give rise to fragments of larger average size (6 kb and greater) under these conditions. It has been reported that some strains in the S. cerevisiae species group contain only Ty2 elements and no Ty1 elements (Fink, Boeke \& Garfinkel, 1986; Boeke, 1989). Some of the strains tested had hybridization patterns consisting only of fragments larger than $6.5 \mathrm{~kb}$ (data not shown), and it is likely that these strains contain only Ty2 elements. The M lanes contain lambda markers, with the sizes in kb shown to the right. 
Table 1. Differences in log likelihood values for models fitted to the distribution of Tyl elements shown in Figure 2.

\begin{tabular}{lll}
\hline Model & Rank & $\begin{array}{l}\text { Difference in Log } \\
\text { likelihood }\end{array}$ \\
\hline DQ & 1 & 0.00 \\
HL & 2 & 0.03 \\
DK & 3 & 0.05 \\
SC & 4 & 0.20 \\
CK & 5 & 0.27 \\
HR & 6 & 0.29 \\
HQ & 7 & 0.38 \\
DL & 8 & 0.68 \\
CQ & 9 & 1.07 \\
HK & 10 & 1.10 \\
DR & 11 & 1.67 \\
SL & 12 & 1.75 \\
RK & 13 & 2.52 \\
CL & 14 & 2.87 \\
HC & 15 & 3.08 \\
\hline
\end{tabular}

Notes: Ty distribution data was truncated at $n=17$ elements (see text for details), and copy numbers were grouped in sets of three (that is, 0-2, 3-5 ...). Log likelihoods were calculated using a branching process model described by Sawyer and Hartl (1986), with two parameters $D(n)=\delta f(n)$, and $T(n)=\tau f(n)$, where $T(n)$ is the transposition rate as a function of copy number, $D(n)$ is the selective effect as a function of copy number, and $\delta$ and $\tau$ are constants. The functional forms of $T(n)$ and $D(n)$ are given in the first column where the first letter refers to the functional form for $T(n)$ and the second letter refers to the functional form for $D(n) . \mathrm{C}: f(n)=1 ; \mathrm{D}: f(n)=1 / \sqrt{ } n ; \mathrm{H}: f(n)=1 / n ; \mathrm{K}: f(n)=n^{3}$; L: $f(n)=n ; \mathrm{Q}: f(n)=n^{2} ; \mathrm{R}: f(n)=\sqrt{ } n ; \mathrm{S}: f(n)=1 / n^{2}$. Models of transposition which assume the functional form $f(n)=C, D, H, R$ and $S$ imply some form of regulation of transposition. All models gave an adequate fit to the data as tested by the $\chi^{2}$ goodness of fit test.

modern wild strains, perhaps aided by some level of horizontal transmission facilitated by occasional matings between haploids from different populations. It is significant that in a total of 119 wild isolates analyzed by us and by Philippsen et al. (1983), no strain was identified containing zero Ty elements. We can imagine that in each isolate, copy number is at an equilibrium, determined by the factors acting to increase copy number and those acting to decrease copy number. Among factors which may act to increase copy number are (replicative) transposition itself and natural selection for individual Ty insertions. Ty transposition may be a regulated function, either autogenously or hostcontrolled, and as discussed above, is modulated by environmental factors. Transposable elements that have been studied in other species have been shown to possess a variety of elaborate copy number control mechanisms (Berg \& Howe, 1989), and certainly it may be expected that Ty elements are no exception. The analysis of the distribution of $\mathrm{Ty}$ elements in natural populations described in the previous section suggests that some sort of copy number control, either host or Ty element-determined, is acting to limit Ty number. Factors which may act to decrease copy number in populations include natural selection against individual Ty insertions as well as loss due to recombination between the two deltas of a Ty element, leaving behind a solo delta in the genome. Such deletions occur at a frequency of $\sim 1 \times 10^{-5} /$ element, and possibly even higher (cf. Picologlou et al., 1988; Rothstein, 1979). Nevertheless, the extreme bottlenecks in effective population number, created by clonal replacements (Koch, 1974), will maintain such deletions at low frequencies - on the order of $1 \times 10^{-5}$, unless they result in a selective advantage. However, there is evidence that delta-delta recombination has been important in reducing $\mathrm{Ty}$ copy number. For example, a strain isolated by $M$. Ciriacy and P. Philippsen that has been shown to contain only one complete Ty element nevertheless contains a large number of solo deltas, which may be considered to be relics of ancient Ty elements.

\section{Transposition and stabilization of Ty elements in the genome}

Although resident Ty elements are relatively stable, being lost at a rate of $\sim 1 \times 10^{-5}$, there is some evidence that the rate of deletion is not constant and can be significantly higher for newly transposed elements (C. Paquin, pers. comm.). Thus, the kinetics of the accumulation of Ty elements in the genome may involve two processes which are formally separable, transposition and stabilization. Figure 4 shows the hybridization spectra for a series of subclones derived from strains, carrying one (Fig. 4 top) and 18 (Fig. 4 bottom) Ty copies, newly transposed into the genome. In both cases, differences between the subclones can be seen for Ty copy number. Whereas a number of sub clones of the strain carrying only one Ty element show increases in Ty number, only decreases were seen in the strain containing 18 copies. When a subclone containing an increase in Ty number (subclone 4, Fig. 4 top) was restreaked, and the hybridization 


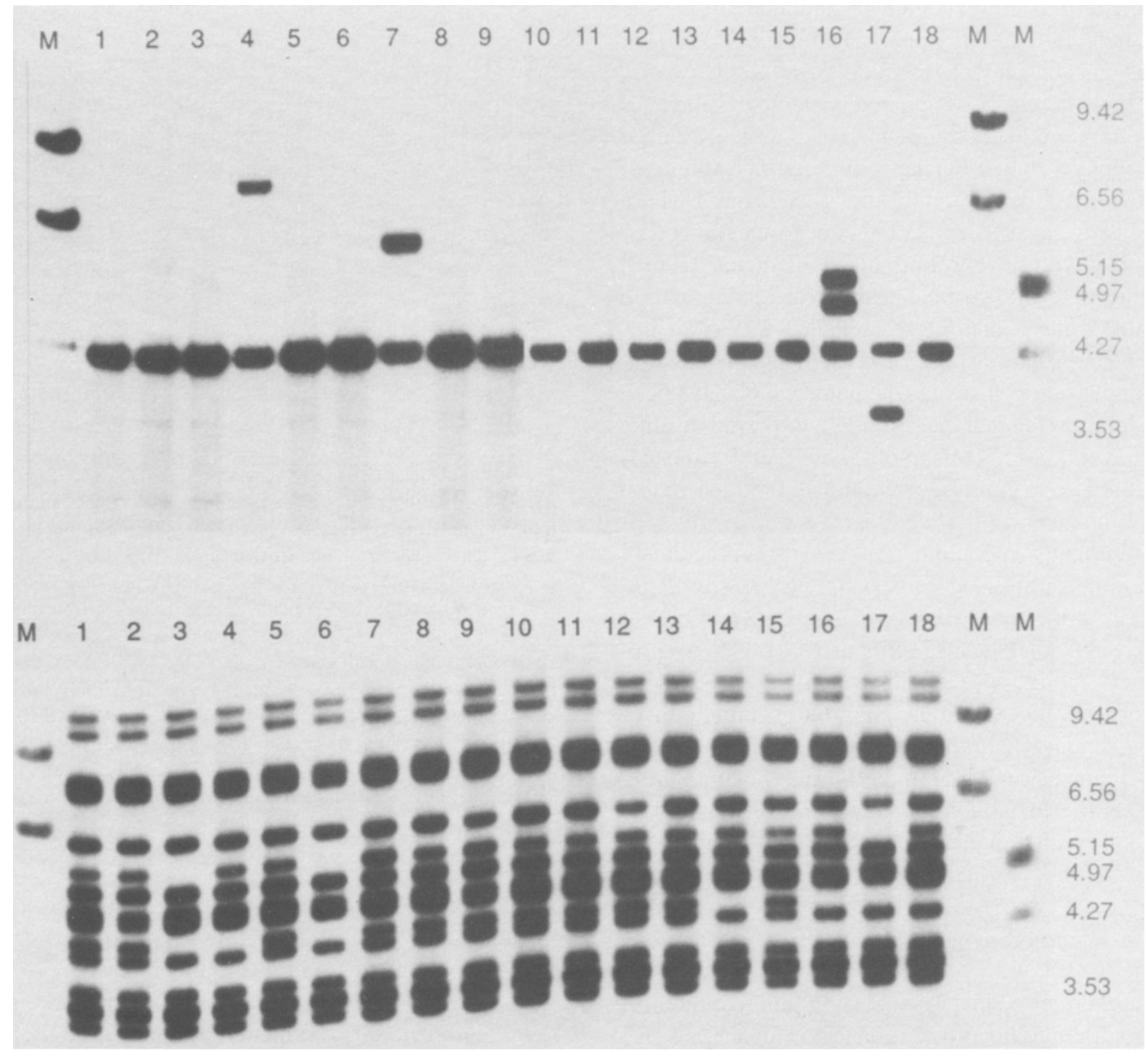

Fig. 4. Instability of Ty 1 subclones of strains with newly integrated elements. The top and bottom panels show hybridization spectra for 18 subclones from the low and high number Tyl strains, respectively, resulting from the first round of growth after Tyl transposition induction. The two strains containing one and 18 newly integrated Ty 1 elements were constructed using the galactose inducible plasmid pGTy1-H3 in a Ty1-less strain of yeast. These strains were streaked to YEPD plates (complex glucose medium), and incubated at $30^{\circ} \mathrm{C}$ until colonies arose. A single subclone was chosen at random from these original colonies, restreaked to a fresh YEPD plate, and the incubation at $30^{\circ} \mathrm{C}$ was repeated. DNA was prepared from individual subclones resulting from the two rounds of growth, and the Tyl number determined by DNA - DNA hybridization. All digestions, and hybridization procedures are as described in Figure 2 , except that here the 5' specific Ty 1 probe was used (Fig. 1, probe 2). Under these conditions, each band represents at least one Tyl element. The single Ty 1 element in the original clone of the top panel migrates at $-4.3 \mathrm{~kb}$ in all the lanes. New bands are seen in lanes $4,7,16$ and 17. Two different exposures of the two halves of the top blot are shown to compensate for unequal DNA loadings in lanes of interest. In the bottom panel, the fragments which were observed to be lost, migrate at $\sim 4.5 \mathrm{~kb}$ and $\sim 5.5 \mathrm{~kb}$. Subclones which lost one or both of these bands are shown in lanes $3,4,6,14,16$ and 17. 
spectra of a set of subclones examined after a second round of growth, the newly transposed element was unstable and was lost in $8 / 18$ clones. However, Ty copy number was apparently stable in subclones of a high number strain which had not experienced Ty copy number changes in the first round of growth (Wilke \& Adams, unpublished data). These results suggest that $i$ ) Tyl-less or low number Ty1 strains with newly introduced elements have a higher rate of Ty1 transposition or recombination than strains containing established Ty1 elements, and $i i)$ newly transposed Ty1 elements may exhibit a higher rate of loss than elements which have been residing in the genome for a longer period of time.

Several workers have observed that Ty transposition is apparently recombinogenic, such that a fraction of the time Ty elements are involved in homologous recombination events immediately prior to or following transposition (Natsoulis et al., 1989; Wilke et al., 1989; Weinstock et al., 1990). It is possible that the instability that we observe represents a persistence of this recombinogenic effect over several generations. Thus, the accumulation of Ty elements in strains containing high numbers of Ty elements may be limited by two separate processes, the instability of new transposition events and the reduction in transposition rate with increasing Ty number.

\section{Evidence for copy number control}

More direct evidence for copy number control would be provided by estimates of increases in Ty copy number following successive rounds of transposition. Since levels of Ty transposition at $30^{\circ} \mathrm{C}$ $\left(1 \times 10^{-9}\right.$ to $\left.1 \times 10^{-10}\right)$ are a small fraction of the mutation rate, copy number control would typically be difficult to demonstrate unless transposition rates were artificially elevated. Figure 5 shows the increase in copy number over five rounds of induction of transposition in strains carrying the plasmid pGTy1-H3 (Boeke et al., 1985). The presence of this plasmid, which contains the yeast GAL1 promoter fused to a transposition-competent Tyl element, allows the induction of high levels of transcription and therefore transposition when the host strain is grown on galactose medium. The results clearly show that at $30^{\circ} \mathrm{C}$, transposition rate is strongly dependent on the number of elements in the genome. Thus, in the first round of transposition

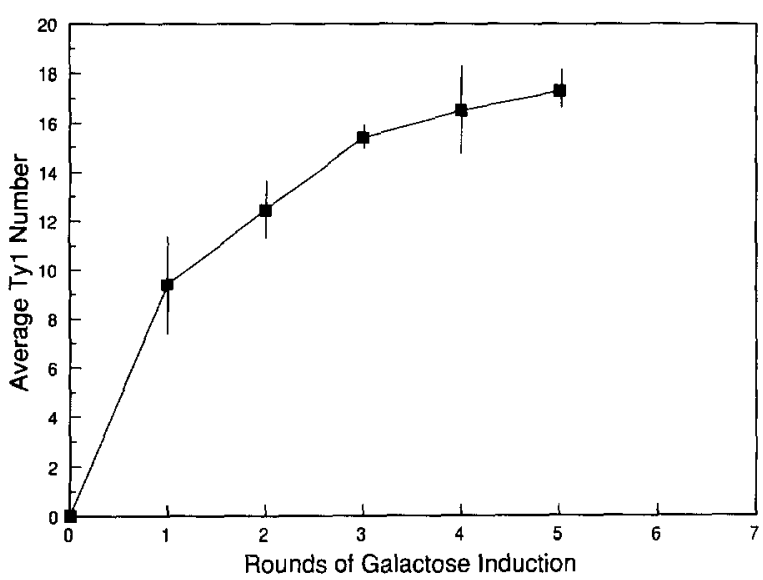

Fig. 5. Continuous galactose induction of the Tyl-less strain transformed with pGTy1-H3. The uninduced Ty1-less strain transformed with the pGTyl-H3 plasmid was streaked to minimal galactose plates and incubated at $30^{\circ} \mathrm{C}$. After colonies appeared, a single colony was restreaked to both a minimal galactose plate, as well as YEPD plate. Subclones $(\sim 16)$ from the YEPD (non-inducing/repressing) plate were analyzed by DNA - DNA hybridization to determine the increase in Ty1 number resulting from the previous round of induction. When new colonies arose on the galactose plate, the process was repeated. The population was maintained on four separate galactose plates, each contributing equally to the sample checked for Tyl number after each round of induction. The vertical line at each point is \pm one standard deviation.

induction, mean copy number increased from 0 to 9.4 elements. However, in subsequent rounds of induction, the increase in Ty1 number became progressively smaller. After five rounds of induction the experiment was terminated because of lack of progress in increasing Ty 1 number. Although the initial establishment of Tyl elements in the population was quite efficient, continued accumulation of greater numbers of elements was apparently limited by the increased copy number.

This massive amount of Ty 1 transposition during the initial induction at $30^{\circ} \mathrm{C}$ in the Ty-less strain is striking because at face value it contrasts sharply with previous observations of Ty 1 activity in laboratory strains containing endogenous Ty 1 elements. In all previous reports, the Ty 1 transposition rate from both endogenous Ty elements and those on inducible plasmids is at least five-fold (Garfinkel \& Strathern, 1991) and usually 20 to 100-fold (Boeke, Styles \& Fink, 1986; Paquin \& Williamson, 1984) greater at low temperature $\left(\leq 22^{\circ} \mathrm{C}\right)$ compared to $30^{\circ} \mathrm{C}$. However, this difference is resolved when 
the change in Ty number is measured during successive rounds of transposition at $18^{\circ} \mathrm{C}$. At this temperature increase in Ty 1 number remained approximately constant over nine rounds of transposition induction, at which point the mean copy number was 30.53 , almost twice that obtained with successive rounds of induction at $30^{\circ} \mathrm{C}$ (Wilke \& Adams, unpublished). Thus, no evidence for copy number control is seen over this range at $18^{\circ} \mathrm{C}$. Stimulation of transposition in non-optimal temperature regimes and under starvation conditions is also seen for transposable elements in $E$. coli (Kretschmer \& Cohen, 1977; Nevers, Reiff \& Saedler, 1977; Cornelis, 1980; Hall, 1988) and may occur for retrotransposons in Drosophila (McDonald, 1989). It has been suggested that a stimulation in transposition under such conditions of stress is an adaptive response generating increased levels of genetic variation, thus enhancing the probability that a mutation occurs permitting or facilitating growth (Stahl, 1988; Hall, 1990).

\section{Accumulation of Ty elements in populations}

Accumulation of Ty elements in populations will obviously be dependent on rates of transposition, but it also will be affected by the selective effects of Ty insertions. For example, if Ty 1 insertions are nearly always deleterious no significant accumulation over time should occur. In this section, we report results of experiments which estimate changes in Ty1 copy number during growth in long-term laboratory continuous culture. Three independent populations were initiated with a single clone containing a single active genomic element, and maintained for almost 1,000 generations. In all three populations Tyl copy number increased over time. Figure 6 shows the data for two of these three populations which were analyzed in detail, one grown in glucose-limited continuous culture, and one grown in serial dilution in complex medium. It can be seen that increase in mean copy number was approximately linear, with no evidence of a reduction in the rate of increase of Tyl copy number. At each time point sampled, including generation zero, variation in Ty 1 number was seen, but with one clonal type present in high frequency. Hybridization spectra indicated that predominant clones isolated at successive time points apparently contained some Ty insertions in common. Thus the predomi-

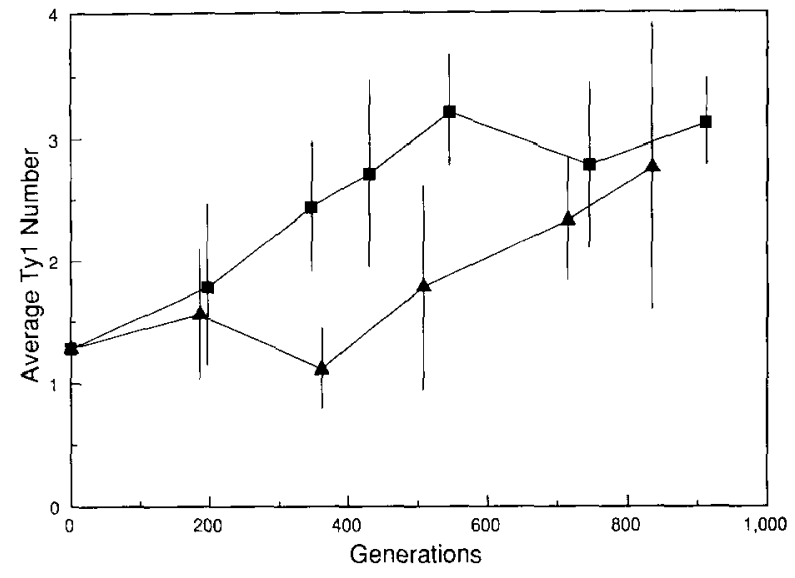

Fig. 6. Ty 1 element increase in long-term populations. See text for general explanation. D-long-term serial dilution in rich (YEPD) medium. The average initial population size was $1.7 \times$ $10^{4}$ cells, while the average population size immediately prior to dilution, to initiate a new cycle was $1.7 \times 10^{9}$ cells. $\mathbf{\Lambda}$-glucoselimited continuous culture, maintained at a dilution rate of $\mathrm{D} \approx$ 0.17 . Population size averaged $1.7 \times 10^{9}$ cells. At each time point, the Ty1 number was determined by DNA - DNA hybridization for a sample of 7-18 clones taken from the cultures, as described in the legends to figures 2 and 4 . The vertical line at each point represents \pm one standard deviation.

nant clones were related to each other genealogically.

Two alternative hypotheses may be considered for the increase in Ty copy number seen in these populations: $i$ ) accumulation of Tyl elements occurs due to a process of transposition and selection, and $i$ ) accumulation of Ty 1 elements occurs solely due to the chance occurrence of a transposition event within an adaptively favored clone (hitchhiking; Maynard Smith \& Haigh, 1974; Kaplan, Hudson \& Langley, 1989). However, in the absence of any selective advantage for individual Ty 1 insertions, the average number of Ty 1 elements may be expected to fluctuate significantly over time, as adaptive mutations occurred in clones containing higher or lower numbers of Tyl elements, and not to increase consistently as seen here. Therefore, these results are most easily explained by assuming that some individual Tyl insertions are selectively favored.

Accumulation of Ty elements has also been reported for populations in which the initial number of Ty elements was high. Cameron, Loh \& Davis (1979) maintained five replicates of a population 
initiated with a single haploid clone of a common laboratory strain (S288C) in serial dilution in rich medium at $37^{\circ} \mathrm{C}$ for one month. In two of the five replicates, one extra Ty band was observed in the hybridization spectra of the terminal clones. New Ty element insertions were also seen in populations maintained in glucose-limited continuous culture for up to 300 generations (Adams \& Oeller, 1986). In populations initiated with a single clone of either a MATa haploid or a MATa/a diploid strain, new Ty elements were observed and their appearance correlated with adaptive shifts in the cultures. However, no accumulation of Ty-elements was seen in $a / \alpha$ diploid populations maintained in either serial dilution or continuous culture (Eibel et al., 1980; Adams \& Oeller, 1986). These results are consistent with the lower transposition rate in $a / \alpha$ diploids (see below).

Although an increase in Ty element copy number is seen in laboratory populations initiated both with low number and with high number strains, the accumulation was clearly more rapid for the populations initiated with low numbered strains. This difference is consistent with the results presented in the previous sections, which showed that variation for increase in Ty 1 number and the transposition rate appear to be strongly dependent on the number of Ty1 elements in the genome.

Ty copy number and mating-type control of transposition

Average Ty copy number in laboratory strains is considerably higher than that in wild isolates. In the 88 strains examined (see Fig. 2), the average Ty number was 17.45 , whereas laboratory strains contain between 25 and 35 Ty elements. An increased number of Ty elements in laboratory strains may be explained by the less stringent nature of the environment allowing strains to accumulate more deleterious insertions. However, the increase may also be due to their (typically) haploid nature and an interaction between the mating type locus and Ty element transposition. Ty 1 mRNA makes up 5 to $10 \%$ of the total mRNA in MATa or MAT $\alpha$ cells, but is 20 fold lower in $M A T a / \alpha$ diploids (Elder $e t$ al., 1980), leading to a significantly decreased transposition rate (Paquin \& Williamson, 1986). Thus, transposition rates in wild isolates, which are predominantly diploid due to their homothallic na- ture, will be expected to be significantly lower than those of laboratory strains. Mating-competent diploid $(a / a, \alpha / \alpha)$ strains have an expression pattern similar to haploids (Elder et al., 1980), indicating that Ty expression may be associated with matingor sporulation-competence (Boeke, 1989).

It is tempting to speculate on the adaptive significance of the interaction between mating-type and transposition rate. In general, diploid populations may be expected to accumulate recessive deleterious Ty-insertions, which have little or no phenotypic effect in the diploid phase. A transition to the haploid phase would then expose these deleterious Ty insertions with potentially serious consequences to survival (cf. Paquin \& Adams, 1983; Kondrashov \& Crow, 1991; Perrot, Richerd \& Valéro, 1991). Thus, the reduction of the transposition rate can be interpreted as an adaptive response to reduce this buildup during the diploid phase of deleterious Ty-insertions which would be inevitably expressed after the transition to the haploid phase of the life cycle.

\section{Selection for and against Ty1 insertions}

Results presented in the previous sections provide indirect evidence for the selective effects of Ty insertions. Direct evidence is difficult to obtain, as the transposition rate is typically on the order of the mutation rate, and the number of transpositions occurring in evolving populations will therefore be limited. Furthermore, since the genomes of laboratory yeast strains already contain large numbers of transposable elements, any determination of the selective roles of such elements may be complicated by heterogeneity in their selective effects, as well as by a possible dosage effect.

To circumvent these problems, Wilke and Adams (1992) constructed populations containing broad distributions ( 0 to 20 elements) for Ty 1 number by using a strain of yeast initially containing zero Ty elements, and the plasmid pGTy1-H3. Since the transposition rate in this system is highly temperature dependent, it was possible to construct genetically variable populations containing different means and variances in Tyl copy number, but with a minimum level of genetic variation caused by other mechanisms. Estimates of the rate of Tyl transposition induced by this plasmid allowed the 
Table 2. Relationship between stationary cell density and Tyl copy number.

\begin{tabular}{llll}
\hline & No induction & $\begin{array}{l}\text { Induction } \\
18^{\circ} \mathrm{C}\end{array}$ & $\begin{array}{l}\text { Induction } \\
30^{\circ} \mathrm{C}\end{array}$ \\
\hline $\begin{array}{l}\text { Mean \# Tyl } \\
\text { elements } \pm \mathrm{SD}^{\mathrm{a}}\end{array}$ & $\begin{array}{l}0.0 \pm 0.0 \\
\mathrm{~N}^{\mathrm{b}}\end{array}$ & $\begin{array}{l}4.3 \pm 2.6 \\
35\end{array}$ & $\begin{array}{l}11.2 \pm 2.7 \\
35\end{array}$ \\
\hline $\begin{array}{l}\text { Mean } \\
\text { Stationary }\end{array}$ & $1.96 \times 10^{7}$ & $1.88 \times 10^{7}$ & $1.80 \times 10^{7 \mathrm{~d}}$ \\
$\begin{array}{l}\text { Cell Density } \\
\text { Range }\end{array}$ & $1.68-2.32$ & $1.51-2.13$ & $0.95-3.08$ \\
& $\times 10^{7}$ & $\times 10^{7}$ & $\times 10^{7}$ \\
$\begin{array}{l}\text { Standard } \\
\text { Deviation of } \\
\text { Stationary } \\
\text { Cell Density }\end{array}$ & $1.5 \times 10^{6}$ & $1.9 \times 10^{6}$ & $4.0 \times 10^{6 \mathrm{e}}$ \\
$\mathrm{N}^{\mathrm{b}}$ & 27 & 30 & 30 \\
\hline
\end{tabular}

Notes: Data from Wilke and Adams (1992).

a - Standard deviation.

b - Sample size.

c-Cells/ml.

d - Significantly smaller than the values for 'No Induction' and 'Induction at $18^{\circ} \mathrm{C}$ ' at $\alpha<0.01$ as tested by the Mann-Whitney Test (Conover, 1971).

e - Significantly larger than the values for 'No Induction' and 'Induction at $18^{\circ} \mathrm{C}$ ' at $\alpha<0.01$ as tested by the Siegel-Tukey Test after correction for location differences (Conover, 1971).

conclusion that at least $90 \%$ of the genetic variation in these populations was due to Tyl insertions. Further details are given in Wilke and Adams (1992).

\section{Evidence that Tyl element insertions are deleteri- ous}

One component of fitness which may be important under limiting resource conditions is the efficiency with which an organism converts that limiting resource into biomass, or cell number. Selection determined by this component of fitness has been termed $K$-selection (MacArthur, 1962). Table 2 shows the relationship between genetic variation for Ty 1 transposition and stationary phase cell density. The results clearly indicate two trends. As the number of newly transposed Ty1 elements increases, the mean stationary phase density decreases. However, both the variance and range in stationary phase density increase. At the highest level of transposition, the range of densities exceeds that for the clones with no transposition, at both ends of the distribution. Comparable results have also been obtained by Boeke, Eichinger and Natsoulis (1991).

These observations indicate that Ty1 transpositions are on average, deleterious. Nevertheless, the significant increase in the variance of stationary phase density indicates that while most Tyl insertions have negative effects on fitness, some may have neutral and positive effects. Given a large number of transposition events, the probability that at least one of these events is deleterious will therefore be high. A corollary to this interpretation is that clones containing multiple transposition events, all of which are neutral or advantageous in effect, will be rare. Clones with high numbers of Ty 1 transposition events and with high stationary phase densities may fall into this category.

\section{Evidence that Tyl insertions are adaptively favored}

To test directly for adaptively favorable Ty 1 insertions, Wilke and Adams (1992) constructed a series of populations, each containing large amounts of variability for Ty 1 copy number, including clones with zero Tyl elements, and grew them in serial dilution culture. Figure 7 shows the distribution of Tyl copy number in these populations at generation 0 . Each population, containing $\sim 1,000$ different clones at generation zero, was maintained in duplicate for 98-112 generations, and at that time the distribution of the number of Tyl elements was determined by DNA - DNA hybridization. The Ty 1 hybridization spectra made it possible to identify closely related clones, and classify them into Ty1 clone families. Table 3 shows the frequency of these clone families at generation zero and at the terminal generations for eight independent populations each maintained in duplicate. Several aspects of these results are noteworthy. $i$ ) The frequency of 0 Ty1-containing clones decreased in the majority of the populations to $\sim 0.0 \mathrm{ii}$ ) The number of Ty 1 clone families in the populations at their termination was drastically reduced in comparison with generation zero. The average number of families present at the termination of the experiments was 2.7 (standard deviation 2.2), whereas at the beginning of the experiments almost every clone tested belonged to a unique family. This loss of variation 


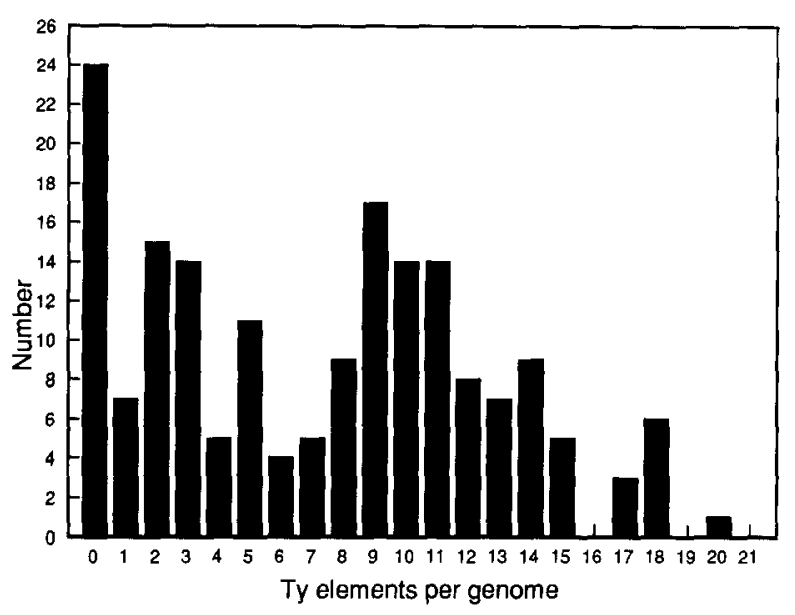

Fig. 7. Distribution of Ty 1 elements in the competition experiments at generation 0 pooled from samples of the 10 populations constructed.

for clone families is exactly the result expected under competitive growth conditions. As the more fit clone families increase in frequency, the less fit families are lost from the population, and the number of clone families is reduced. iii) The same Tyl families of clones were selected in both replicates of each population, indicating that the variants selected during competitive growth were present when the replicate populations were initiated.

Considering that most $(\sim 90 \%)$ of the genetic variation in the populations was due to Tyl transposition, that much of this variation was shown to have on average a negative impact on a continuously varying trait, and that clones containing no Tyl elements were present in the populations at generation zero, the overall pattern of these results can only be explained by postulating a direct selective advantage for the Tyl insertions in the clones which predominated.

\section{Change in Tyl number over time in a structured environment}

The results shown in Table 3 suggest that in a simple homogeneous environment clones containing specific Tyl insertions are selected, and that variation for Tyl copy number is dramatically reduced. This result may be expected in an environment where the resources are equally distributed, and individual clones are in direct competition with all other clones in the population. However, natural environments are highly structured and considerably more complex. To simulate such an environment, one population containing large amounts of Tyl variation was maintained on plate culture in physically variable conditions. The distribution of Ty1 copy number in the population at generation zero was similar to that shown in Figure 7. The plates were incubated outdoors, with no shielding from direct sunlight, between the months of July and August, to take advantage of the relatively mild but variable climatic conditions which prevail in the southeast portion of lower Michigan. The plates were wrapped tightly with parafilm to maintain sterility, and placed inside a wire cage to provide protection from inquisitive squirrels and pigeons. Growth was sustained by continually passing the grown colonies to fresh plates. The time between successive passages ranged from 6 to 21 days.

The results, shown in Table 3, differ markedly from those obtained in the liquid cultures. Whereas in liquid culture (populations $\mathrm{A}-\mathrm{H}$ ) the mean and variation for both Tyl number and for the number of distinct Ty 1 clone families decreased markedly as the populations evolved, the patterns of change in the plate-culture population (population I) were quite different. At generation 106, all clones containing $>$ zero Ty elements were unique. At generation 211 , of the 18 clones examined, the number of distinct Ty1 clone families was 16 . Nevertheless, the mean and standard deviation of Ty number did change markedly (data not shown) indicating that selection had occurred.

It thus appears that growth on a solid substrate (the normal environment for terrestrial yeasts) permits the maintenance of much higher levels of genetic variation than growth in homogeneous liquid medium. It is tempting to believe that the diurnal cycling of temperature and insolation were significant factors contributing to the continuing high levels of diversity for Ty 1 copy number, as ultraviolet light has been shown to increase the levels of Ty mRNA, and low temperature greatly enhances Tyl transposition. However, a spatial structuring of the environment may serve to reduce selective changes occurring in populations by isolating different clones from direct competition. It is perhaps not surprising that the Ty hybridization patterns of wild strains show high levels of variation compared to widely dispersed domestic laboratory and brewery 
Table 3. The effect of selection on the number and frequencies of Ty1 clones and clone families.

\begin{tabular}{|c|c|c|c|c|c|c|}
\hline \multirow[b]{2}{*}{ Population } & \multicolumn{3}{|c|}{ Number of families } & \multirow[b]{2}{*}{$\begin{array}{l}\text { Frequency of }{ }^{d} \\
\text { Terminal } \\
\text { families at } \\
\text { generation } 0\end{array}$} & \multirow[b]{2}{*}{$\begin{array}{l}\text { Frequency of } \\
0 \text { Ty clones } \\
\text { in terminal } \\
\text { samples }\end{array}$} & \multirow[b]{2}{*}{$\begin{array}{l}\text { Concordance } \\
\text { between } \\
\text { replicates }\end{array}$} \\
\hline & $\begin{array}{l}\text { Generation }^{\mathrm{a}} \\
0\end{array}$ & $\begin{array}{l}\text { Terminal }^{\mathrm{b}} \\
\text { samples }\end{array}$ & $\begin{array}{l}\text { Common }^{\mathrm{c}} \\
\text { Families in } \\
\text { terminal } \\
\text { samples }\end{array}$ & & & \\
\hline A & $\geq 13$ & 85 & 2 & 0.06 & $0.17 \quad 0.29$ & 0.51 \\
\hline B & $\geq 11$ & 23 & 2 & 0.06 & $0.67 \quad 0.61$ & 0.33 \\
\hline $\mathrm{C}$ & $\geq 14$ & 62 & 1 & 0.00 & $0.00 \quad 0.00$ & 0.33 \\
\hline $\mathrm{D}$ & $\geq 16$ & 11 & 0 & 0.00 & $0.00 \quad 0.00$ & 0.00 \\
\hline $\mathrm{E}$ & $\geq 13$ & 44 & 2 & 0.00 & $0.00 \quad 0.00$ & 0.33 \\
\hline $\mathrm{F}$ & $\geq 13$ & 11 & 1 & 0.00 & $0.17 \quad 0.00$ & 0.91 \\
\hline $\mathrm{G}$ & $\geq 13$ & 21 & 1 & 0.00 & $0.06 \quad 0.00$ & 0.91 \\
\hline $\mathbf{H}$ & $\geq 13$ & 11 & 1 & 0.00 & $0.00 \quad 0.00$ & 1.00 \\
\hline \multirow[t]{2}{*}{ I } & $\geq 13$ & $12^{\mathrm{g}}$ & - & - & $0.33^{g}$ & - \\
\hline & & $16^{\mathrm{h}}$ & - & - & $0.11^{\mathrm{h}}$ & - \\
\hline
\end{tabular}

Notes: Data from Wilke and Adams (1992). Populations A-H were maintained in serial dilution in rich medium at $30{ }^{\circ} \mathrm{C}$. Population I was maintained on plate culture in a physically variable environment. Each passage or plating of the culture was carried out as follows. With the aid of a sterile glass spreader, $10 \mathrm{ml}$ of medium (YEPD) was used to wash the colonies from the plates. Cell density was determined with a particle counter (Coulter ZM), after sonicating briefly to separate clumped cells. Portions of a dilution series were plated, so that the number of viable cells could be estimated on the more densely covered plates comprising the population. The number of colony forming units plated for each passage ranged from $7.7 \times 10^{3}-3.4 \times 10^{4}$.

a Numbers of clone families containing $>0$ Ty 1 elements. Sample sizes for each population were 17 or 18 clones. Therefore almost all clones at generation 0 were unique, and the estimated number at the beginning of the experiments must be considered minimum estimates.

${ }^{\mathrm{b}}$ Numbers of clone families containing $>0$ Ty1 elements for both replicates.

${ }^{c}$ Number of clone families, containing $>0$ Ty 1 elements in the terminal samples, that are common to both replicates.

${ }^{d}$ Total frequency of the clone families identified in the terminal samples, at generation 0 .

e Frequencies of the clones containing zero Ty elements in the terminal samples. Numbers are given for both replicates of populations A-H.

${ }^{\mathrm{f}}$ The concordance between clone families, $\mathrm{C}$, is defined as

$$
\begin{gathered}
C=\sum_{\mathrm{i}=1}^{m}\left(n_{\mathrm{i} 1}+n_{\mathrm{i} 2}\right) / N, \\
n_{\mathrm{i} 1}, n_{\mathrm{i} 2}>0
\end{gathered}
$$

where $n_{\mathrm{i} 1}$ and $n_{\mathrm{i} 2}$ are the numbers of clones assayed in the first and second replicates respectively, belonging to the $i$ th family $(i=1 \ldots m)$, and $N$ is the total number of clones assayed in both replicates.

g Population I at generation 106.

${ }^{\mathrm{h}}$ Population I at generation 211.

strains. The competition imposed on domestic yeast by their frequent growth in liquid medium is likely to homogenize and deplete the genetic variation within these populations. It is possible that the variation observed for Ty elements in wild strains represents a reservoir of genetic variation for fitness directly attributable to the integration of the elements themselves. On the other hand, the Ty variation in wild strains may simply reflect the degree to which genetic variation can be maintained in populations of microorganisms that reproduce clonally in relative isolation from each other.

\section{Concluding remarks}

The presence of Ty elements in all strains examined and the broad variation among wild isolates of $S$. cerevisiae suggest an early origin and long-term genetic stability within the genome. Yet they still retain their mutagenic capabilities, though there has been some suggestion that a proportion of Ty elements resident in the genome are inactive and no longer retain the ability to transpose (Boeke et al., 1988; Curcio, Sanders \& Garfinkel, 1988). The genetic and environmental variables affecting Ty transposition rate suggest that it may vary signifi- 
cantly during the history of a yeast population. The studies presented here indicate that there is a high rate of Tyl movement after the elements have been initially introduced into a strain, resulting in an increase in Tyl number in evolving yeast populations. Once Tyl elements have been established, they rarely transpose under the optimal genetic and environmental conditions of diploidy and warm temperature. However, changes in mating competence, temperature, and exposure to mutagens all increase the the rate of Tyl transposition. These brief periods of increased transposition may be responsible for the observed long-term persistence of many of the Ty elements within the $S$. cerevisiae species group, in the face of selection and spontaneous deletion.

The fairly limited range of Ty number in yeast strains (no strains with less than 1 or more than $\sim 40$ Ty elements have been reported) also implies the existence of forces acting to control copy number. The data showing that an increase in Tyl number results in both a deleterious effect on a continuously varying component of fitness and a decrease in the ability to induce transposition (at $30^{\circ} \mathrm{C}$ ) indicate that the copy number is likely to be controlled by both regulation of transposition, determined by the host and/or the Ty element itself, as well as by selection against deleterious mutations.

The wide variation of Ty number and position within the genomes of natural and domestic strains indicates that maintenance of the elements is a dynamic, ongoing process, resulting in at least some genetic differentiation between populations. The possible evolutionary importance of this genetic variation in Ty copy number is intimated by the increase in Tyl number we observe in evolving populations in the laboratory, and by the predominance of specific Tyl clones in duplicates of populations containing large amounts of variation for Ty1.

\section{Acknowledgements}

We thank J. Boeke for the gift of the plasmid pGTy1-H3, P. Philippsen and M. Ciriacy for the Ty1-less strain 337, J. De Angelo of the Stroh Brewery Company for brewing strains, and S. Sawyer for a computer program which allowed the calculation of the values in Table 1 . We also thank $R$.
B. Helling and R. F. Rosenzweig for helpful discussion, and S. Herman and L. Joventino for technical assistance. This work was supported in part by U.S. Public Health Service grant, GM30959. E. M. acknowledges support from the Alexander-vonHumboldt Foundation.

\section{References}

Adams, J. \& P. W. Oeller, 1986. Structure of evolving populations of Saccharomyces cerevisiae: Adaptive changes are frequently associated with alterations involving mobile elements belonging to the Ty family. Proc. Natl. Acad. Sci. USA 83: 7124-7127.

Adams, S. E., J. Mellor, K. Gull, R. B. Sim, M. F. Tuite, S. M. Kingsman \& A. J. Kingsman, 1987.The functions and relationships of Ty-VLP proteins in yeast reflect those of mammalian retroviral proteins. Cell 49: 111-119.

Barnett, J. A., R. W. Payne \& D. Yarrow, 1983. Yeasts, characteristics and identification. Cambridge University Press, Cambridge.

Berg, D. E. \& M. M. Howe, 1989. eds. Mobile DNA. American Society for Microbiology, Washington, D.C.

Boeke, J. D., 1989. Transposable elements in Saccharomyces cerevisiae, pp. 335-374 in Mobile DNA, edited by D. E. Berg and M. M. Howe. American Society for Microbiology, Washington D.C.

Boeke, J. D., D. J. Eichinger, D. Castrillon \& G. R. Fink, 1988. The Saccharomyces cerevisiae genome contains functional and non-functional copies of transposon Ty1. Mol. Cell, Biol. 8: 1432-1442.

Boeke, J. D., D. J. Eichinger \& G. Natsoulis, 1991. Doubling Tyl element copy number in Saccharomyces cerevisiae: host genome stability and phenotypic effects. Genetics 129: 1043-1052.

Boeke, J. D. \& D. J. Garfinkel, 1988, Yeast Ty elements as retroviruses, pp. 15-39 in Viruses of Fungi and Simple Eukaryotes, edited by Y. Koltin and M. J. Leibowitz. Marcel Dekker Inc, New York.

Boeke, J. D., D. J. Garfinkel, C. A. Styles \& G. R. Fink, 1985. Ty elements transpose through an RNA intermediate. Cell 40: 491-500.

Boeke, J. D., C. A. Styles \& G. R. Fink, 1986. Saccharomyces cerevisiae SPT3 gene is required for transposition and transpositional recombination of chromosomal Ty elements. Mol. Cell. Biol. 6: 3575-3581.

Cameron, J. R., E. Loh \& R. W. Davis, 1979. Evidence for transposition of dispersed repetitive DNA families in yeast. Cell 16: 739-751.

Chao, L., C. Vargas, B. B. Spear \& E. C. Cox, 1983. Transposable elements as mutator genes in evolution. Nature 303: 633-635.

Chao, L. \& S. M. McBroom, 1985. Evolution of transposable elements: An IS10 insertion increases fitness in E. coli. Mol. Biol. Evol. 2: 359-369.

Charlesworth, B. \& C. H. Langley, 1989. The population genetics of Drosophila transposable elements. Annu. Rev. Genet. 23: 251-287. 
Clare, J. J., M. Belcourt \& P. J. Farabaugh, 1988. Efficient translational frameshifting occurs within a conserved sequence of the overlap between the two genes of a yeast Ty 1 transposon. Proc. Natl. Acad. Sci. USA 85; 6816-6820.

Clare, J. J. \& P. J. Farabaugh, 1985. Nucleotide sequence of a yeast Ty element: evidence for an unusual mechanism of gene expression. Proc. Natl. Acad. Sci. USA 82: 2829-2833.

Clark, D. J., V. W. Bilanchone, L. J. Haywood, S. L. Dildine \& S. B. Sandmeyer, 1988. A yeast sigma composite element, Ty3, has properties of a retrotransposon. J. Biol. Chem. 263: 1413-1423.

Conover, W. J., 1971. Practical Nonparametric Statistics. John Wiley, New York.

Cornelis, G., 1980. Transposition of Tn951 (Tnlac) and cointegrate formation are thermosensitive processes. J. Gen. Microbiol. 117: 243-247.

Curcio, M. J., N. J. Sanders \& D. J. Garfinkel, 1988. Transpositional competence and transcription of endogenous Ty elements in Saccharomyces cerevisiae: implications for regulation of transposition. Mol. Cell. Biol, 8: 3571-3581.

Doolittle, W. F. \& C. Sapienza, 1980. Selfish genes, the phenotype paradigm and genome evolution. Nature 284: 601-603.

Eibel, H., J. Gafner, A. Stotz \& Philippsen, 1980. Characterization of the yeast mobile element Ty1. Cold Spring Harbor Symp. Quant. Biol. 45: 609-617.

Eibel, H. \& P. Philippsen, 1984. Preferential integration of yeast transposable element Ty into a promoter region. Nature 307 : 386-388.

Elder, R. T., T. P. St. John, D. T. Stinchcomb \& R. W. Davis, 1980. Studies on the transposable element Tyl of yeast. I. RNA homologous to Ty1. Cold Spring Harbor Symp. Quant. Biol. 45: 581-584.

Elder, R. T., E. Loh \& R. W. Davis, 1983. RNA from the yeast transposable element Ty1 has both ends in the direct repeats, a structure similar to retrovirus RNA. Proc. Natl. Acad. Sci. USA 80: 2432-2436.

Errede, B., T. S. Cardillo, F. Sherman, E. Dubois, J. Deschamps \& J. Wiame, 1980. Mating signals control expression of mutations resulting from insertion of a transposable repetitive element adjacent to diverse yeast genes. Cell 22: 427 436.

Farabaugh, P. J. \& G. R. Fink, 1980. Insertion of the eukaryotic transposable element Ty 1 creates a 5 bp duplication. Nature 286: 352-356.

Fink, G. R., J. D. Boeke \& D. J. Garfinkel, 1986. The mechanism and consequences of retrotransposition. Trends Genet. 2: $118-123$

Finnegan, D. J., 1989. Eukaryotic transposable elements and genome evolution. Trends Genet. 5: 103-107.

Fitzpatrick, B. J. \& J. Sved, 1986. High levels of fitness modifiers induced by hybrid dysgenesis in Drosophila melanogaster. Genet. Res. 48: 89-94.

Gafner, J., E. M. De Robertis \& P. Philippsen, 1983. Delta sequences in the $5^{\prime}$ region of yeast tRNA genes. EMBO J. 2: 583-591.

Gafner, J. \& P. Philippsen, 1980. The yeast transposon Ty1 generates duplicates of target DNA in insertion. Nature 286: 414-418.

Garfinkel, D. J., J. D. Boeke \& G. R. Fink, 1985. Ty element transposition: reverse transcriptase and virus-like particles.
Cell 42: 507-517.

Garfinkel, D. J. \& J. N. Strathern, 1991. Ty mutagenesis in Saccharomyces cerevisiae Meth. Enzymol. 194: 342-361.

Giroux, C. N., J. R. A. Mis, M. K. Pierce, S. E. Kohalmi \& B, A. Kunz, 1988. DNA sequence analysis of spontaneous mutations in the SUP4-o gene of Saccharomyces cerevisiae. Mol. Cell. Biol. 8: 978-981.

Goebl, M. G. \& T. D. Petes, 1986. Most of the yeast genomic sequences are not essential for cell growth and division. Cell 46: 983-992.

Hall, B. G., 1988. Adaptive evolution that requires multiple spontaneous mutations. I. Mutations involving an insertion sequence. Genetics 120: 887-897.

Hall, B. G., 1990. Spontaneous point mutations that occur more often when advantageous than when neutral. Genetics 126: 5-16.

Hansen, L. J., D. L. Chalker \& S. B. Sandmeyer, 1988. Ty3, a yeast retrotransposon associated with tRNA genes, has homology to animal retroviruses. Mol. Cell. Biol. 8: 52455256.

Hansen, L. J. \& S. B. Sandmeyer, 1990. Characterization of a transpositionally active Ty 3 element and identification of the Ty3 integrase protein. J. Virol. 64: 2599-2607.

Iida, H., 1988. Multistress resistance of Saccharomyces cerevisiae is generated by insertion of Ty into the $5^{\prime}$ coding region of the adenylate cyclase gene. Mol. Cell. Biol. 8: 5555-5560.

Kaplan, N. L., R. R. Hudson \& C. H. Langley, 1989. The 'hitch-hiking' effect revisited. Genetics 123: 887-899.

Kingsman, A. J. \& S. M. Kingsman, 1988. Ty: A retroelement moving forward. Cell 53: 333-335.

Kleckner, N., 1990. Regulation of transposition in bacteria. Annu. Rev. Cell Biol. 6: 297-327.

Klein, H. L. \& T. D. Petes, 1984. Genetic mapping of Ty elements in Saccharomyces cerevisiae. Mol. Cell. Biol. 4: 329-339.

Koch, A. L., 1974. The pertinence of the periodic selection phenomenon to prokaryotic evolution. Genetics 77: 127 142.

Kondrashov, A. S. \& J. F. Crow, 1991. Haploidy or diploidy: which is better? Nature 351: 314-315.

Kretschmer, P. J. \& S. N. Cohen, 1977. Selected translocation of plasmid genes: frequency and regional specificity of translocation of the Tn3 element. J. Bacteriol. 130: 888-899.

Kurlandzka, A., R. F. Rosenzweig \& J. Adams, 1991. Identification of adaptive changes in an evolving population of Esch erichia coli: the role of regulatory changes with highly pleiotropic effects. Mol. Biol. Evol. 8: 261-281.

Laski, F. A., D. C. Rio \& G. M. Rubin, 1986. Tissue specificity of Drosophila $P$ element transposition is regulated at the level of mRNA splicing. Cell 44: 7-19.

Lewontin, R. C., 1974. The Genetic Basis of Evolutionary Change. Columbia University Press, NY.

Liebman, S. W. \& S. Picologlou, 1988. Recombination associated with yeast retrotransposons, pp. 63-90 in Viruses of Fungi and Simple Eukaryotes, edited by Y. Koltin and M. J. Leibowitz. Marcel Dekker Inc., NY.

Lopilato, J. \& A. Wright, 1990. Mechanisms of activation of the cryptic bgl operon of Escherichia coli K12, pp. 435-444 in The Bacterial Chromosome edited by $\mathrm{K}$. Drlica and $\mathbf{M}$. Riley. American Society of Microbiology Publications. 
Washington, D.C.

MacArthur, R. H., 1962. Some generalized theorems of natural selection. Proc. Natl. Acad. Sci. USA 231: 123-128.

Mackay, T. F. C., 1985. Transposable element-induced response to artificial selection in Drosophila melanogaster. Genetics 111: 351-374.

Mackay, T. F. C., 1986. Transposable element-induced fitness mutations in Drosophila melanogaster. Genet. Res. 48: 77 87.

Maimer, E., 1990. Taxonomie und Oekologie von Hefen aus Frucht und Fruchtzubereitungen. Unpublished Ph.D. thesis, Technische Universität München-Weihenstephan.

Maynard Smith, J. \& J. Haigh, 1974. The hitch-hiking effect of a favourable gene. Genet. Res. 23: 25-35.

McClanahan, T. \& K. McEntee, 1984. Specific transcripts are elevated in Saccharomyces cerevisiae in response to DNA damage. Mol. Cell. Biol. 4: 2356-2363.

McDonald, J. F., 1989. The potential evolutionary significance of retroviral-like transposable elements in peripheral populations, pp. 190-205, in Evolutionary Biology of Transient Unstable Populations, edited by A. Fontdevila, SpringerVerlag, New York.

McDonald, J. F., 1990. Macroevolution and retroviral elements. BioScience 40: 183-191.

Mellor, J., S. M. Fulton, W. W. Dobson, S. M. Kingsman \& A. J. Kingsman, 1985a. A retrovirus-like strategy for expression of a fusion protein encoded by yeast transposon Ty1. Nature 313: 243-246.

Mellor, J., A. J. Kingsman \& S. M. Kingsman, 1986. Ty, an endogenous retrovirus of yeast? Yeast 2: 145-152.

Mellor, J., M. H. Malim, K. Gull, M. F. Tiute, S. McCready, T. Dibbayawan, S. M. Kingsman \& A. J. Kingsman, 1985b. Reverse transcriptase activity and Ty RNA are associated with virus-like particles in yeast. Nature 318: 583-586.

Misra, S. \& D. C. Rio, 1990. Cytotype control of Drosophila P element transposition: The $66 \mathrm{kd}$ protein is a repressor of transposase activity. Cell 62: 269-284.

Modi, R., L. H. Castilla, S. Puskas-Rozsa, R. B. Helling \& J. Adams, 1992. Genetic changes accompanying increased fitness in evolving populations of Escherichia coli. Genetics 130: 241-249.

Morawetz, C., 1987. Effect of irradiation and mutagenic chemicals on the generation of $A D H 2$-constitutive mutants in yeast. Significance for the inducibility of Ty transposition. Mut. Res. 177: 53-60.

Muller, F., K. H. Bruhl, K. Freidel, K. V. Kowallik \& M. Ciriacy, 1987. Processing of Tyl proteins and formation of Ty1 virus-like particles in Saccharomyces cerevisiae. Mol. Gen. Genet. 207: 421-429.

Natsoulis, G., W. Thomas, M. Roghmann, F. Winston \& J. D. Boeke, 1989. Transposition in Saccharomyces cerevisiae is nonrandom. Genetics 123: 269-279.

Nevers, P., H. J. Reiff \& H. Saedler, 1977. Mutations affecting IS 1-mediated deletion formation in E. coli. In, DNA Insertion elements plasmids and episomes, pp. 125-128 edited by A. Bukhari, J. Shapiro and S. Adhya. Cold Spring Harbor Laboratory Press, Cold Spring Harbor, N.Y.

Orgel, L. E. \& F. H. C. Crick, 1980. Selfish DNA: the ultimate parasite. Nature 284: 604-607.

Oyen, T. B. \& O. S. Gabrielsen, 1983. Non-random distribution of the Ty1 elements within nuclear DNA of Saccharomyces cerevisiae. Fed. Eur. Bioch. Soc. 161: 201-206.

Paquin, C. E. \& J. Adams, 1983. Frequency of fixation of adaptive mutations is higher in evolving diploid than haploid populations. Nature 302: 495-500.

Paquin, C. \& V. M. Williamson, 1984. Temperature effects on the rate of Ty transposition. Science 226: 53-55.

Paquin, C. \& V. M. Williamson, 1986. Ty insertions at two loci account for most of the spontaneous antimycin A resistance mutations during growth at $15^{\circ} \mathrm{C}$ of Saccharomyces cerevisiae strains lacking $A D H 1$. Mol. Cell. Biol. 6: 70-79.

Pasyukova, E. G., E. S. Belyaeva, G. L. Kogan, L. Z. Kaidanov \& V. A. Gvozdev, 1986. Concerted transpositions of mobile genetic elements coupled with fitness changes in Drosophila melanogaster. Mol. Biol. Evol. 3: 299-312.

Pasyukova, E. G., E. S. Belyaeva, L. E. Ilyinskaya \& V. A. Gvozdev, 1988. Outcross-dependent transpositions of copia-like mobile genetic elements in chromosomes of an inbred Drosophila melanogaster stock. Mol. Gen. Genet. 212: 281-286.

Pedersen, M. B., 1985. DNA sequence polymorphisms in the genus Saccharomyces. II. Analysis of the genes RDNI, HIS4, LEU2 and Ty transposable elements in Carlsberg, Tuborg and 22 Bavarian brewing strains. Carlsberg Res. Commun. 50: 263-272.

Pedersen, M. B., 1986. DNA sequence polymorphisms in the genus Saccharomyces. III. Restriction endonuclease fragment patterns of chromosomal regions in brewing and other yeast strains. Carlsberg Res. Commun. 51: 163-183.

Pedersen, M. B., 1988. The use of nucleotide sequence polymorphisms and DNA karyotyping in the identification of brewer's yeast strains and in microbiological control, pp. 180-194 in Modern Methods of Plant Analysis, New Series Vol 7, Beer Analysis, edited by H. F. Linskens and J. F. Jackson. Springer-Verlag, NY.

Perrot, P., S. Richerd \& M. Valéro, 1991. Transition from haploidy to diploidy. Nature 351: 315-317.

Philippsen, P., H. Eibel, J. Gafner \& A. Stotz, 1983. Ty elements and the stability of the yeast genome, pp. 189-200 in Gene expression in Yeast. Proceedings of the Alko Yeast Symposium Helsinki, edited by M. Korhola and E. Vaisanen. Foundation for Biotechnical and Industrial Fermentation Research, Helsinki.

Picologlou, S., N. Brown \& S. W. Liebman, 1990. Mutations in $R A D 6$, a yeast gene encoding a ubiquitin-conjugating enzyme, stimulate retrotransposition. Mol. Cell. Biol. 10: 1017-1022.

Picologlou, S., M.E. Dicig, P. Kovarik \& S. W. Liebman, 1988. The same configuration of Ty elements promotes different types and frequencies of rearrangements in different yeast strains. Mol. Gen. Genet. 211: 272-281.

Rolfe, M., A. Spanos \& G. Banks, 1986. Induction of yeast Ty element transcription by ultraviolet light. Nature 319: 339340 .

Rose, M. \& F. Winston, 1984. Identification of a Ty insertion within the coding sequence of the $S$. cerevisiae URA3 gene. Mol. Gen. Genet. 193: 557-560.

Rothstein, R., 1979. Deletions of a tyrosine tRNA gene in $S$. cerevisiae. Cell 17: 185-190.

Sandmeyer, S. B., L. J. Hansen \& D. L. Chalker, 1990. Integra- 
tion specificity of retrotransposons and retroviruses. Annu. Rev. Genet. 24: 491-518.

Sawyer, S. \& D. L. Hartl, 1986. Distribution of transposable elements in prokaryotes. Theoret. Pop. Biol. 30; 1-16.

Sawyer, S. A., D. E. Dykhuizen, R. F. Dubose, L. Green, T. Mutangadura-Mhlanga, D. F. Wolczyk \& D. L. Hartl, 1987. Distribution and abundance of insertion sequences among natural isolates of Escherichia coli. Genetics 115: 51-63.

Scherer, S., C. Mann \& R. W. Davis, 1982. Reversion of a promoter deletion in yeast. Nature 298; 815-819.

Shrimpton, A. E., T. F. C. Mackay \& A. J. Leigh Brown, 1990. Transposable element-induced response to artificial selection in Drosophila melanogaster, molecular analysis of selected lines. Genetics 125: 803-811.

Simchen, G., F. Winston, C. A. Styles \& G. R. Fink, 1984. Ty mediated gene expression of the LYS2 HIS4 genes of Saccharomyces cerevisiae is controlled by the same SPT genes. Proc. Natl. Acad. Sci. USA 81: 2431-2434.

Stahl, F. W., 1988. Bacterial genetics. A unicom in the garden. Nature 335: 112-113.

Stavenhagen, J. B. \& D. M. Robins, 1988. An ancient provirus has imposed androgen regulation on the adjacent mouse sex-limited protein gene. Cell 55: 247-254.

Stucka, R., H. Lochmuller \& H. Feldmann, 1989. Ty4, a novel low-copy number element in Saccharomyces cerevisiae: one copy is located in a cluster of Ty elements and tRNA genes. Nuc. Acids Res. 17: 4993-5001.

Syvanen, M., 1984. The evolutionary implications of mobile genetic elements. Ann. Rev. Genet. 18: 271-293.

Taguchi, A. K. W., M. Ciriacy \& E. T. Young, 1984. Carbon source dependence of transposable element-associated gene activation in Saccharomyces cerevisiae. Mol. Cell. Biol. 4: 61-68.

Toh-e, Y., Y. Kaneko, J. Akimaru \& Y. Oshima, 1983. An insertion mutation associated with constitutive expression of repressible acid phosphatase in Saccharomyces cerevisiae. Mol. Gen. Genet. 191; 339-346.

Voelker, R. A., J. Graves, W. Gibson \& M. Eisenberg, 1990. Mobile element insertions causing mutations in the Drosophila suppressor of sable locus occur in DNase I hypersensitive subregions of $5^{\prime}$-transcribed nontranslated sequences. Genetics 126: 1071-1982.

Warmington, J. R., R. B. Waring, C. S. Newlon, K. J. Indge \& S. G. Oliver, 1985. Nucleotide sequence characterization of Ty 1-17, a class II transposon from yeast. Nuc. Acids Res. 13: 6679-6693.

Weinstock, K. G., M. F. Mastrangelo, T. J. Burkett, D. J. Garfinkel \& J. N. Strathern, 1990. Multimeric arrays of the yeast retrotransposon Ty. Mol. Cell. Biol. 10: 2882-2892.

Wilke, C. M. \& J. Adams, 1992. Fitness effects of Ty transposition in Saccharomyces cerevisiae. Genetics 131: 31-42.

Wilke C. M., S. H. Heidler, N. Brown \& S. W. Liebman, 1989. Analysis of yeast retrotransposon Ty insertions at the CAN1 locus. Genetics 123: 655-665.

Williamson, V. M., E. T. Young \& M. Ciriacy, 1981. Transposable elements associated with constitutive expression of alcohol dehydrogenase II. Cell 23: 605-614.

Wilson, W., M. H. Malim, J. Mellor, A. J. Kingsman \& S. M. Kingsman, 1986. Expression strategies of the yeast retrotransposon Ty: a short sequence directs ribosomal frameshifting. Nuc. Acids Res. 14: 7001-7016.

Xu, H. \& J. D. Boeke, 1990. Host genes that influence transposition in yeast: the abundance of a rate tRNA regulates Ty 1 transposition frequency. Proc. Natl. Acad. Sci. USA 87: 8360-8364.

Youngren, S. D., J. D. Boeke, N. J. Sanders \& D. J. Garfinkel, 1988. Functional organization of the retrotransposon $\mathrm{Ty}$ from Saccharomyces cerevisiae: Ty protease is required for transposition. Mol. Cell. Biol. 8: 1421-1431. 